\title{
The Effect of Body Mass on Aging and Health in
}

\section{Nigeria}

\author{
Heoma Nsirim-Worlu Ph.D \\ Owapiriba p. Jackreece Ph.D \\ University of Port Harcourt, Faculty of Social Sciences, Department of Sociology \\ Email:worlu@yahoo.com,owapiriba.jack@uniport.edu.ng
}

Doi:10.5296/jsr.v5i2.6898 URL: http://dx.doi.org/10.5296/jsr.v5i2.6898

\begin{abstract}
Body mass in this context is synonymous with body weight. The body mass index of an individual is always considered in relation to a person's age, sex and height. The physical appearance of an individual can be described by an onlooker as fat or slim and the interest of this work is to find out how body mass can affect health and ageing, knowing that body weight can mean different things to different persons based on the environment and cultural settings. This is a descriptive study and its source of data is derived from primary and secondary sources and literature from outside Nigeria serve as means of validating this work; and six hundred persons were sampled using the probability sample technique. The framework of this study is the life course approach in that, from birth to death, the human body undergoes changes and the observed changes are imperative. This work proposes that the more fat or bulkier a person is, the faster he ages and the more the associated health challenges. This work finds out that, several forces affect body mass (weight) and the amount of body mass directly affects health and the health status determines or affects ageing. Albeit, the study recommends that though certain factors that affect ageing are genetically determined, individuals should deliberately resolve to maintain healthy weight through the choice of healthy living. That is the life style of a people when modified through available knowledge; persons will attain quality health and by extension age gracefully.
\end{abstract}

Keywords—Body Mass, Health, Ageing, Body Image And Life Style

\section{INTRODUCTION}

Body weight which we wish to refer to in this work as body mass is a veritable index in the measurement of an individual's wellness, wealth and even care in Africa in the past. That is, it is perceived as a status symbol; then how robust or fat a woman is goes a long way to adjudge her husband and family' wealth and also how loving and caring the family is. In more than four decades ago, bulky girls were preferred for marriages to slim built ones and so families and communities performed different rituals and ceremonies to ensure that their daughters and wives maintained robust physical bodily appearances.

The health implication of performing ceremonies just to make females look robust this paper wants to reason that the people did not understand; for instance, the occasion of fattening ceremony was a common practice and it had different names in different communities. In 
lkwerre ethnic nation it is known as ojiji, whereas it is known as irria in Kalabari kingdom. This fattening ceremony in a way can be a rite of passage from childhood to adulthood and can also serve dual purposes; one, it is a means to prepare young girls for marriage and also care for women specially following childbirth, puerperium and nursing period; it further depicts a family's wealth and prestige.

However, with explosion in knowledge, revolution in medicine, science and technology, and globalisation it has become obvious to some, that excess body mass is definitely not a mark of health, wealth and/or status. Truly, body mass varies as individuals vary but the more an individual's body mass, the more that individual may face numerous life threatening health challenges; to that (Insel and Roth 2006) state that "achieving and maintaining a healthy body weight is a serious public health challenge in the United States and a source of distress for many Americans."

There are factors that account for the weight of an individual, and different people (culture) have different views about body weight and size. With aging studies emerging as a new field of academic endeavour in Nigeria, this work is set out to investigate the impact of body mass on health and ageing.

\section{STATEMENT OF THE PROBLEM}

According to (National Institute on Aging, 2008), "normal aging can be distinguished from disease" an idea we accede to; although people's physical appearance change as individuals grow older and the body structure continuously declines over time, but these changes do not automatically translate to diseases such as diabetes, hypertension or dementia. At this point, the argument is, the bulkier or fatter an individual is, determines how (s)he ages or put differently, the body weight of an individual affects in part how the person ages. Bulky individuals are observed to be prone to aging faster and aging is also observed as not being without health challenges, an idea (Moody 2012) describes as secondary aging; this in part accounts for why different people age differently.

Some people age normally without diseases; while others are observed to be frail and have varying degrees of disease challenges. The fact that it is very common sight to see people who are very fat with mobility challenges of varied magnitude all over; accounts for one of the prompting factors prompting us to study this topic. Some other health conditions commonly observed in people who age faster than their age cohorts are that they are down with hypertension, diabetes and cardiovascular diseases or heart related disorders. This stand is also supported by (N.I.A 2008) and it posits that "a number of disorders that typically occur in old age are due to disease processes, not normal aging."

Given to observed changes in family structure and the current economic realities, it is necessary to undertake this study, so that as a matter of utmost importance, we shall be able to educate the generality of the people on how to maintain appropriate weight, reduce diseases and thereby bring about normal aging processes; defraught of diseases which will in turn make the older people less dependent on family members for support and assistance. This idea is corroborated by (Aboderin in Hoff 2007). The forthcoming section contains some questions which will assist us to have clearer understanding to what this work is set out to investigate. 


\section{RESEARCH QUESTIONS}

In order to elicit more information on the topic under discussion, a few questions are asked and they are:-

- Does the body size of a person determine his health and aging process?

- Do majority of the people understand the effect of weight on ageing?

- Should communities be discouraged from performing rites that make people accumulate large body mass?

\section{OBJECTIVE OF THE STUDY}

Objective of a study is the main aim which the study is set to achieve; therefore the objective of this study is divided into two parts; the broad and specific objectives. The broad objective of this work is to let people know that the bulkier a person's weight, the more his/her ageing process is surrounded by serious and numerous health challenges. The specific objectives are:-

- To make people understand that a person's weight will affect his/her health status.

- To investigate how a person's body size will influence ageing process.

- To expose what people will do in order to maintain a healthy body weight/mass.

\section{SIGNIFICANCE OF THE STUDY}

The importance of this study cannot be underestimated, in that it will contribute both theoretically and practically. Theoretically in the sense that, it will enhance the theoretical base of ageing studies both in Nigeria and abroad. Practically, it will assist practitioners in the care of the elderly and the general populace to acquire knowledge on how to maintain a healthy body mass throughout their life course.

This work proposes that the more body mass a person has, the more the individual will age faster and also present with age related diseases. The next section is devoted to review of relevant literature which is arranged under the following subheads/units; brief description of aging, what factors determine health, link between aging, body mass and body image; what can be done to maintain a healthy body mass and finally the effect of body mass on ageing.

\section{A BRIEF DESCRIPTION OF AGEING}

Ageing, though seen by many as a natural and physiological process; is a misnomer or an albatross to some others. Different people perceive ageing or old age differently; the way an individual views old age, greatly affects how he ages and handles the changes that accompany ageing.

Generally, some characteristics serve as windows to diagnosing old age and its processes; some of the characteristics to ageing may include but are not limited to grey hair, wrinkles, alteration in body size; shape and sometimes mobility. To add credence to this is 
www.newsmax.com which states that "the thought of aging conjures some perceptions; wrinkles, grey hair, a slightly stooped posture, perhaps some 'senior moments' of forgetfulness."

Ageing also causes changes to occur in the cells, tissues, organs and systems of the body; as manifest in reduction in vision, hearing and even eating, digestion, absorption and elimination; this can be described as biological changes. Some who are not prepared for ageing at this period present with low self esteem, depression, cardiovascular changes; for example hypertension, stroke, cardiovascular accident; aggression and some more.

In continuation therefore, American Geriatrics Society Foundation for Health on aging; states that "the effects of aging can be seen in everything from our vital signs (like blood pressure, temperature, pulse), to our skin, to the bones and joints, to our cardiovascular, digestive systems etc". It is interesting to note that some aging changes begin easily in life; therefore, the forces that affect ageing shall be discussed in the forthcoming section as they are numerous and more importantly as we all age individually, at different rates, degrees and also experience many common effects of aging differently.

\section{POSSIBLE FORCES THAT INFLUENCE AGEING}

Ageing which is a naturally instituted mechanism and it starts from birth and continues till death; so, there are things that can affect ageing and its processes. Some of the factors are and may include: -

1) GENETICS- The genetic make-up of an individual determines how he/she ages and that is why some persons look older than their chronological ages; and we think, the deoxyribonucleic acid (DNA) signature is responsible for this and this makes a whole lot of differences observable among people, families and even races. To support this is (Owen 2006); who describes DNA as genetic maps which varies more widely from person to person.

2) NUTRITION- It is the science which teaches on the choice of food in any given circumstances, it therefore concerns the quality and quantity of food. Different nutritional statuses of a group of people determine how they age; the nutritional status of a person is predicated on the combination of all the classes of food-protein carbohydrate, fats, oil, fruits, vegetable and water. It therefore implies that right choices and combination of food items contribute to the ageing processes of the people. To substantiate the above, reference is made to low income countries, especially those in crisis ridden areas in Africa for instance, Sudan and Ethiopia; how they look older than their contemporaries in other parts of the world; the major culprit to that look is their nutritional intake which is anything but near balanced. To further emphasize this point is American Journal of Clinical Nutrition (2014); who establishes the relationship between food intake and body weight. 
3) IDEOLOGY- This simply refers to a peoples' world view, which comprises belief, value and more. Most African women are socialised to assume that, following marriage and delivery of children that a woman has become old and should henceforth dress in a certain way. This expected dressing mode makes them look older than their peers in other parts of the world. Conversely, an American or European woman following marriage and child delivery, still appears young, smart and attractive; because she continues to engage in various life and figure maintaining programmes. It is also known that a person's physical appearance depicts his/her social status; those who are in high income group because of their lifestyle look younger than their contemporaries, in this instance, all that they indulge in only delay ageing but do not stop it. We must admit that the view of Africans especially Nigerians towards maintaining bulky body weight; what is considered as obesity by Americans is changing tremendously in the present circumstance.

4) LIFE STYLE- Social aspects of a person's life affects his/her health and age in that, his/her indulgences and choices such as smoking, alcohol consumption, type of exercises, parity of a woman are veritable determinants of ageing and its processes. Most Africans are poor and so the quality of choice of food to consume, they are also known to maintain very active life styles and so are not mostly obesed but, with interactions becoming global and the demonstration effect which the life styles of the rich and Americans have on the society, the trend is changing and what we observe now is more men having abdominal size of more than forty inches. The reason being that men are becoming more sedentary, consume large quantities of alcohol and engage in less fit keeping exercises; on the other hand women are taking up jobs that are more energy consuming, feed poorly and may not visit the physician early in case of any disease condition. This observation is supported by a statement from www.ncbi.nlm.nih.gov/pubmed which states that "there is a relationship between life style, residential area and body weight"; this then means that a peoples life style affect their body weight and ageing processes.

5) HEALTH/DISEASE INDEX- Either the health or disease status of a person goes a long way to influencing ageing and its processes. A healthy person will age normally and gracefully; while an ill one ages faster; especially a person suffering from a chronic or terminal disease, for example, an individual suffering from cancer of any form and also critical and dangerous state of Acquired Immune Deficiency Syndrome (AIDS). There are so many factors which individually or collectively affect health and ageing in people of different regions and we are sure this particular entry cannot cover all; however, other factors that affect ageing in the view of Chuckrow (2010) are in 
the areas of exposure to radiation, quality of nutrition, exercise type, insomnia, excessive sexual activity, smoking and alcohol consumption.

\section{FORCES THAT INFLUENCE HEALTH}

In this section, we shall briefly review the factors that influence health; Health according to World Health Organisation (WHO) in 1978 is "a state of complete physical, mental, social and spiritual wellbeing and not merely the absence of disease or infirmity". This definition is all embracing and complex, yet, it serves as a yardstick of measuring the health status of individuals and groups.

Be that as it may, many factors interplay to bring about health and they are considered herein as determinants of health. For instance, genetics/inherited factors, culture, age, sex, level of education, income and wealth and above all lifestyle.

\section{GENES/INHERITED FACTOR}

These are the genes/signatures that parents transfer to their offspring. These genes are immutable and permanent which is why it is common to hear that some diseases run in families or are familial; a typical example is the sickle cell disease which is known as African disease, this illness accounts for more than $25 \%$ of causes of death in Africa. Of note also is the fact that the colour of a person's eye, height and weight are mostly genetically determined. To add credence to the fact that genes play very important role in the health and ageing process of a person is the work of Lynch; Lynch and Shaw (2011) on "hereditary gastrointestinal cancer syndromes".

\section{CULTURE}

Culture simply expressed is the "totality of a people's way of life." It includes material and immaterial aspects of life and it is transferred from generation to generation, most times through oral communication. The choice of food and lifestyle of people are along their cultural line and so affect the people's health and ageing; and the people's world view or ideology has its effect. The way a people view life can affect how they access available health opportunities and the attendant in- equalities in health care services (Harris, Holden, Chen (2010). In agreement with the discussion on ground is Helman (2001); who establishes a link between culture, health and illness, therefore, the understanding derived from this nexus will assist the scholars to understand health problems in a variety of cultural and social settings.

\section{AGE}

An individual's age- which is the chronological period contributes to the person's health. Moody (2012), therefore, defines ageing as $\operatorname{xxxxxxxx~You~may~recall~that~we~have~stated~}$ earlier that ageing is a natural and physiological process which starts from birth to death, that it can be delayed but not stopped. On that premise, as an individual gets older, the cells of the body begin to experience degenerations; the rapidity with which the cells replace themselves is predicated on genetic makeup, underlying disease, childhood exposures, nutritional status and the view about ageing. This further goes to explain that certain disease conditions are common within certain age bracket; for instance, hypertension and stroke mostly regarded as 
diseases of the elderly, while diphtheria, pertusis and tetanus are considered as infant killer diseases.

\section{SEX}

Is the division or classification of humans based on their biological and physiological indices; and it divides the society into two distinctive groups; males and females. The sex of an individual accounts for his/her ageing process; of which the hormones in an individual are easily pointed to. The effect of estrogen and androgen on the individuals predisposes each to different kinds of diseases. For instance (Mudali \& Dobis 2004) affirm that testosterone has effect on the body and health of males.

\section{LEVEL OF EDUCATION, INCOME, AND LIFESTYLE}

The above give individuals ample opportunities to life choices that is; by way of what to eat, drink, what to wear and where to live; and the types of games and recreation they will participate in. The education and income levels of an individual in no small measure affect the person's health; in that, the choice of place and residence type, nutrition and many more are dependent solely on the above and they in turn contribute to how the individual ages.

A person's lifestyle also is a very important pointer in the maintenance of health and wellness. By choice an individual chooses to be healthy or not. What do we mean? A person can wilfully decide to engage in such activities that will pose a threat to his/her well being. For instance, the fellow can decide to associate with people who indulge in binge drinking and eating, who do not participate in any form of exercises; this idea is supported by WHO report (2003) edited by Wilkinson \& Marmot. The foregoing briefly discussed factors and more contribute to the health of an individual and the ideas are also supported by http://www.cdc.gov/mmwr/preview/mmwrhtml/mm481 and http://www.stateoftheair.org.

\section{DETERMINANTS OF BODY WEIGHT}

Body mass, as stated earlier shall be used interchangeably with body weight. Body weight is therefore, defined as the total body mass in relation to the height and age of the individual. It is a daily sight to observe different people with different heights and body sizes. Also observable is the fact that peoples body mass vary according to geographical location.

In all humans, there are two known types of fat that make up the body size and they are known as "essential fat and "non-essential fat." Essential fat according to (Insel \& Roth 2006) is the fat in the body necessary for normal body functioning, they include lipids or fats, incorporated in the nerves, brain, heart, lungs, liver, and mammary glands. While non-essential fat, is extra fat reserves stored in the body which exists primarily within adipose tissue or fat cells, often located just below the skin and around major organs.

Several and varying factors account for the amount of fat an individual stores; they are gender, age, heredity, metabolism, diet and activity level. It is obvious that women have more body fat than men; the female hormone is viewed as being responsible for that. Women tend to deposit fat around their hips and thighs and this accounts for her feminine shape which Insel and Roth describe as 'pear shape', while the males deposit more fat around their abdomen 
which they also describe as 'apple shape'. The areas of fat deposit in these groups of people are responsible for the unique differences in the shape of males and females. It is also observed that the genetic or inherited factor accounts for a person's weight; that is, bulky body mass runs in family.

Metabolic rate of a person contributes to his body mass. If an individual consumes high carbohydrate based food, participates in little or no exercises and is sedentary by occupation, the tendency that he/she will deposit plenty fat tissue which may contribute to morbidity risk is high. This is what Davison etal (2002); refer to "fat gain can also result in functional limitations."

The geographical region of a group of people can affect their body weight or physical appearance. People from a particular area have different perceptions about weight; for instance in some areas in Nigeria, the weight of a woman speaks volumes about the care, affection and wealth she receives from her family of orientation or procreation. That accounts for why women in the olden days were prepared for puberty, marriage and maternity by housing them, feeding them at short intervals, restricting them from engaging in any form of physical activities. At the expiration of the fixed time, the females are celebrated and paraded for people to attest to their well being. In areas, increase in body mass is cherished and gratified. This aspect of traditional ceremony or cultural practice can affect the health of a person as he/she gets older. Remember, it is easy to accumulate fat but much more difficult to reduce or manage gained weight.

To affirm this view is Kyle, et al (2001) who posit that 'the ageing process is accompanied by significant changes in body composition and these changes have considerable impact on the health and well being of the elderly'.

\section{WHAT ACCOUNTS FOR A PERSON'S BODY IMAGE}

What then is body image? Body image is a very important aspect in ageing studies to concern ourselves with in that; the way a person views his body mass or weight will go a long way to affecting his ageing process in part or in whole.

Therefore, body image can be the combination of the following ideas; how we perceive our bodies visually, how we feel about our physical appearance i.e. how we think and talk to ourselves about our bodies, our sense of how other people view our bodies, our sense of our bodies in physical space, our level of connectedness to our bodies, by Andersen \& Holbrook (2000); all the preceding ideas we accent to. It therefore means that, so many things can account for how a person views his/her body and some of those we adduce may be: - media, influence, gender, social status (position), friends and family.

It is not uncommon to view on television screens or hear on radio, how a person who is slim has become Miss World or that; this kind of news upsets those who are fat and bulky and majority view themselves negatively in the process, they may develop one form of eating disorder e.g. bulimia and anorexia nervosa. These are common in the Western societies; but, with the influence of I.C.T, some females in Africa especially have become very conscious of their body image thereby discarding the traditional belief that the bulkier a female, the better care and affection she receives from her family and spouse.

Conversely, it is generally believed that females should have slender built, because they are 
supposed to be admired and fancied. This perception has in great measure been the major cause of challenges women have in trying to ensure that they keep slim, so, those whose genetic conditions cannot guarantee their being slim view themselves negatively and they in turn practice whatever they can ranging from aggressive physical exercise, starvation and even self induction of vomiting. It is this perception of slender built that make some females view themselves as sex objects, a posture which we vigorously campaign against at any available opportunity. In Nigeria today, males develop muscles so much that some are called 'bouncers'; this also is about body image. It is believed that males are expected to have well developed and expanded muscles around their chests, biceps and thighs as propagated by superman and batman films.

The social position of an individual accounts for how he views him/her self image. Those of low socio-economic standards care less about their body mass and it serves as status symbol; while those who are highly placed socially employ great deal of measures to get trimmed, this is what Cash (1997) calls image workout and Insel \& Roth (2006); opine that currently, most Americans are not overweight because they are dissatisfied with their body image and do many things to remain in shape including getting cosmetic surgery.

\section{EFFECT OF BODY WEIGHT ON AGING AND HEALTH}

In this unit attempt will be made to review the relationship between body weight, aging and health; and this paper is of the view that the foregoing concepts are closely linked since man is at the centre of the discourse. That is why we agree with the view of (Insel \& Roth 2006) that, a basic list of important behaviours and health contribute to the health and by extension the aging process such as:-

- Having a sense of responsibility for your own health and taking an active rather than a passive stance toward your life.

- Maintain high self esteem and mentally healthy ways of interacting with other people.

- $\quad$ Eating well, exercising and maintain healthy weight.

- Understanding the natural process or processes of aging and accepting the limits of human existence.

- Understanding how the environment affects your health and aging and taking appropriate actions to improve it.

It hence goes to state that because body mass is affected by some factors which are genetic, environmental and social ageing starts from birth to death, the action of the individual immensely contributes to his/her body mass, health and then age and aging process. Furthermore, there are some recorded health risks associated with excess body fat e.g. obesity which is inadvertently responsible for the incidents of coronary heart disease (CHD), high blood pressure, diabetes etc; which rear their ugly head in old age.

\section{HOW TO MAINTAIN HEALTHY BODY AND SHAPE}


As we get older, our metabolic rate slows down; and this makes it harder for an individual to burn off calories, and excess body weight can increase the risk of heart diseases, stroke and certain cancers. Body shape is important as well, since both men and women who carry more weight around their abdomens have higher risk of heart attack and stroke than those who carry extra weight around their hips.

The view according to Insel and Roth (2011) of which we support is the fact that "wellness cannot be prescribed by physicians and other health care professionals but they can provide information, advice and encouragement. but the rest is up to each of us."

It goes to portend that it is very important for each and everyone to strive to understand his genetic make- up and this knowledge when obtained, the person will make appropriate effort to also combine the knowledge gained from the other professionals to keep fit.

These professionals can be:-

- A nutritionist- a professional who teaches his client how to combine available food items (ingredients) in order to get quality food for consumption in order to maintain health and wellness.

- A physical exercise manager- helps an individual to acquire appropriate skill and exercise for health.

The physician/health professional serves as a "gate keeper" (Schaefer, 2001) to the individual. He makes diagnosis of any ailment and then prescribes appropriate medication which the patient or individual is expected to use religiously.

The individual in question can voluntarily decide to enrol in some keep-fit-initiative programmes. Membership of healthy clubs will assist the person(s) to discard behavioural patterns that may encourage excess body mass; which in turn will lead to diseases or disabilities and also facilitate or reduce ageing processes.

The discussed actions to maintain weight and health can suffix for what Dansinger in Insel \& Roth regards as a "balanced approach" and it comprises of;

- Set reasonable goals, as even small amounts of weight loss benefit health.

- Reduce intake of saturated and Trans fats, refined carbohydrates and added sugars.

- Incorporation of sixty or more minutes of physical activity into your daily routine \& formal exercise program brings about health and fitness benefits.

- Choose a healthy dietary pattern that works for you over the long term. In agreement with this stand is UNECA report (2007); which states that 'while the need for caloric intake decreases with age, the requirements for fluids, protein, most vitamins and minerals remain the same or even increase.' Therefore, a balanced diet with plenty of fluids, a high proportion of fibres, vegetables and fresh fruit, good regular meals, are very significant in the health and wellness of the aging.

Also needed as an aspect of physical exercise for the elderly is the participation in such 
activities as household chores or works, walking which does not need special training and skill, dancing, cycling and even gardening. These, increase action of the heart, body muscles, sight and even mental functioning.

The theoretical frame of this study is the life course approach which is an aspect of the functionalist perspective. The life course approach according to Settersten in (Novak 2012) incorporates social interaction and social structure within its framework and it bridges the gap in both micro-level and macro-levels of analysis.

Life course approach is adopted here because in the view of Elder and Johnson in (Novak, 2012) there are five principles of the life course which are:-

- Human development and aging take place throughout life.

- History and location shape an individual's life.

- Life transitions and events vary depending on when they take place in a person's life.

- Individuals are linked to others and live interdependently.

- Individuals give shape to their lives by taking action and making choices.

The above five principles are confirmatory to the fact that aging starts from the moment a person is born until his death when it stops, and throughout this period of progress in an individual's life; where the person resides and his life experiences collectively shape his life choices and indulgences. It also exposes that, people are connected to one another through family, social organisation, which in turn accounts for the actions he/she would take in order to live a useful and acceptable life.

\section{LIMITATIONS OF THE STUDY}

There are bound to be challenges in every study and for this particular paper aside the usual and constant challenges; those of importance to us are as described below: - the major issue is that not much is done by way of research on ageing and its related issues and so the paucity of literature in this area is unquantifiable. It is also necessary to state that we had difficulty in the use of the word "fat"; knowing quite well that such a word is viewed as derogatory by Americans but we have to use it because fat here is not viewed as obesity as in America rather, as quality of life. Another difficulty is the use of the concept body weight instead of body mass index (BMI); the latter word was not used as international best practice requires because most people in the communities studied neither heard nor knew anything about body mass index and how to arrive at it.

\section{METHODOLOGY}

This work utilizes the survey method in gathering the information used, and the material was collected from documentations and review of relevant literature which were from other clines especially American writers, journals and books. Therefore, the data source is purely secondary; but, in an attempt to validate this work we purposively interviewed five hundred respondents from Rivers State and the responses we collated assisted us in providing 
information as generated by the research questions. The method of analysis is qualitative in that, the data is derived from other people's documentation and no materials found in the environment under study. The respondents were from two major ethnic nationalities in Rivers State, that is, Kalabari and lkwerre people; Kalabari is the riverine area, while lkwerre is the upland part of Rivers State respectively. Two hundred and fifty respondents each were interviewed from each ethnic group, both males and females; for the purposes of generating baseline information in this field. The information gathered was presented in percentage.

\section{DISCUSSION OF FINDINGS}

Having cautiously gone through the documents at our disposal, we discovered that there is a direct link between body mass/weight, health and ageing. In Nigeria, those who are considered as fat have the challenges of mobility, wobbling or wasting skin texture as they grow older as against their age cohorts who have slimmer body structure. This view is also held by Dong Block and Samuel (2004); who state that the activities a person engages in goes a long way to determine his health. The available data show that most fat people sit for longer hours and engage in near or non physical exercises; and so their aging processes are faster; not just that only, they also age with more health challenges or conditions.

Identified also, is that although fatness or bulky body weight is genetically determined in part, most fat people, engage in what we call eating 'junk food'-food with poor nutritional quality. Eating of junk food has become prevalent in Nigeria and it is highly accepted by a lot of people now than before because, our society is on the fast lane of transiting from traditional society to a modern industrialised one; which makes it difficult for most people not to have time to select, prepare and cook meals that are traditional and nourishing. The kinds of food considered as junk are; burger, meat pie, indomie noodles, spaghetti and many more.

The preparations of these food types are very easy and less time consuming and stress free. Food with poor nutritional quality would involve eating excess starch fortified; for instance, fufu, yam, rice, ripe plantain. The end product of such food items is glucose and in normal health conditions, excess glucose (glycogen) is deposited in the adipose tissue of the body thereby contributing to the body mass.

This study further shows that, most fat people present or suffer from mobility problems. The most common mobility challenges are arthritis which can be osteoarthritis or rheumatoid arthritis (Arthritis is the inflammation or disorder that involves one or more joints). Arthritis can be as a result of degeneration of the joint tissues or can be due to autoimmune diseases. This disease condition is fraught with severe pain, which is why those affected find it difficult to participate in any useful physical exercises.

Exercise helps to keep individuals fit and maintain quality and stable health. To support this idea is UNECA (2007) Report on Ageing and Physical Activity, which argues that physical activity can be fun and so should ideally be conducted in a group setting or with friends, thus increasing social contacts and social integration.

Further, physical activity in older people has been shown to increase muscle strength, balance, joint suppleness and overall physical co-ordination. Physical exercise is a very important tool to maintaining a living weight or body mass; therefore such exercises like walking, swimming, cycling etc. should be encouraged. It is pertinent to mention at this point that the 
above listed exercises are known in the world of sports as aerobic exercises. Aerobic exercises are those that cause increase in inhalation, in any of the forms when aerobic exercises are religiously and judiciously carried out; the participant is known to be healthy. It is better to practice aerobic exercise than to engage in muscle straining exercises. Such exercises are not always recommended to every young adult much more the elderly; those exercises are known to cause strain and tear in the muscles.

Physical activity also has favourable effects on blood pressure and body weight and therefore reduces the risk of heart disease, osteoporosis, certain cancers, diabetes and falls. Finally, it is true that a person's body mass affects the health and aging process, but that individual has a role to play in maintaining health and thereby age properly.

Morbidity is the rate of occurrence of diseases in people and/or community. This work discovered that fat people are prone to more illnesses than those with normal body mass. Bulky body mass is known to put a lot of pressure or load on most of the essential organs of the body like the heart and such disease presentations as heart failure, and stroke are common. The rate of metabolism is also high; and they present with diseases of the pancreas which is identified generally as diabetes. There are types of diabetes, the most known and talked about is that which affects people who are older in age.

It is also necessary to emphasize that, such lifestyle as binge drinking and eating, indiscriminate consumption of drugs, substance abuse and above all those traditional practices of which ojiji and irria are part should be discouraged forthwith. Such lifestyle indulgences expose people to health challenges; and it has been stated earlier that, the presence of health challenges affect ageing.

RECOMMENDATION- In the light off the above therefore, we recommend that every person should take it as a point of concern to keep his/her body mass within normal range and this will in turn influence his health and aging process positively with minimal morbidity incidences, this can be done successfully by working on the social and lifestyle factors as they affect health and aging.

This can be achieved by the choice of what to eat, type of physical exercise to participate in, discouraging traditional practices that enhance increase in body weight, holding a positive body image and seeking professional attention from the appropriate quarters in case of any ailments and finally, view ageing as a normal and natural process which must surely happen no matter what scientific or medical technique employed. To be able to maintain healthy body mass by majority, it can be achieved through health education and campaigns which will bring about attitudinal change in both the young and old who will see through the veil of traditional practices and fad in the society; which are the main culprits that were identified as the leading causes to people's body mass aside the genetic factors and the associated health and ageing challenges that were discussed.

\section{ACKNOWLEDGEMENTS}

We are most grateful to University of Port Harcourt, National Universities Commission (NUC), and Dave Omokaro Foundation for having aroused our academic interests toward the study of issues concerning the elderly in Nigeria which is currently at the rudimentary stage. 
Not to be forgotten by any means is the University of North Texas whose platform was used to transmit this immeasurable knowledge in this new field of academic endeavour. Finally we sincerely appreciate our family members for their patience and believe in our capabilities and their trust in God Almighty who saw us through our sojourn in US.

\section{REFERENCES}

American Journal of Clinical Nutrition; www.ajcn.nutriton/content. Retrieved April, 2014. Andersen, A.E; Cohn, L; \& Holbrook. (2000). Making Weight. Men's Conflicts with Food, Weight, Shape \& Appearance. Carlsbad, C.A. Gurze Books.

Cash, T.F (1997). The Image Workbook: An 8-step Program for learning to Like Your Looks. Oakland, C.A; New Harbinger.

Chuckrow, R (2010). www.chuckrowtaichi.com/Aging.html

Davison et al (2002). Percentage of Body Fat \& Body Mass Index are Associated with Mobility Limitations in People Aged 70 \& Older from NHANES III. Journal of the American Geriatrics Society 2002. DOI: 10.10461/j.1532-5415.2002.50505.x. Vol 50 ,

Issue 11, PG 1802-1809.

Dong, L.G. Block and S. Mandel (2004). Activities Contributing to Total Energy Expenditure in

The United States Internal Journal of Behavioural Nutrition and Physical Activity 1 (4).

Harris K, Holden C, Chen M. Background Information on Nutritional Indicators for Social Determinants of Health. Paper Presented to the Secretary's Advisory Committee on National Health Promotion \& Disease Prevention Objectives for 2020. National Opinion

Research Centre.

Helman, C.G. (2001). Culture, Health and Illness. London, Arnold Holder.

Hoff, A. (2007). Summer Newsletter by the research committee (RCII) on the Sociology of Aging of the International Sociological Association (ISA). Oxford, Oxford Institute of Ageing.

http://www.cdc.gov/mmwr/preview/mmwrhtml/mm481

http://www.stateoftheair.org

HU, F.B. etal (2003). Television Watching and Other Sedentary Behaviours in Relation to Risk

Of Obesity \& Type II Diabetes Mellitus in Women. Journal of the American Medical Association 289(14):1785-1791.

Hutchinson (1985). Transforming Body Image. California, Crossing Press; Downloaded August, $5^{\text {th }}, 2013$.

Insel, P.M \& W.T. Roth (2006). Core Concepts in Health. New York. McGraw-Hill Companies,

Inc.

Kyle et al (2001). Total Body Mass, Fat Mass, Fat-Free Mass \& Skeletal Muscle in Older

People: Cross-Sectional Differences in 60-year Old Persons. Journal of the American 
Geriatrics. DOI:10.1111/j.1532-5415-2001.49272.x. Vol 49, Issue 12. PG1633-1640

Lynch, H.T, J.F. Lynch \& T.G Shaw (2011); in www.ncbi.nlm.nih.gov.Retrieved in April, 2014.

Moody, H. (2012).Ageing: Concepts and Controversies. United States of America, Pine Forge Press.

Mudali \& Dobis (2004) http/www.doi.org/10.1010/j.mad.2004

National Institute on Aging (2008) www.nia.nih.gov/Health\&Aging

Novak, M (2012). Issues in Aging. Boston. Pearson Education.

Owen, J. (2006) in www.nationalgeographic.com/news; retrieved April 2014.

Schaefer, R.T (2001). Sociology. McGraw-Hill Companies, Inc. New York.

United Nations Economic Commission for Africa (2007). The State of Older People in Africa;

Regional Review and Appraisal of the Madrid International Plan of Action.

Wilkinson R, Marmot M editors. Social Determinants of Health: the Solid Facts. 2nd Ed.

Copenhagen. World Health Organisation.

http://www.euro.who.int/_data/assets/pdf/file/005/98438/e81384.pdf[PDF-470KB]

www.newsmax.com

www.nchi.nlm.nih.gov/pubmed; retrieved April, 2014. 